Hydrol. Earth Syst. Sci., 17, 2569-2579, 2013

www.hydrol-earth-syst-sci.net/17/2569/2013/

doi:10.5194/hess-17-2569-2013

(C) Author(s) 2013. CC Attribution 3.0 License.

\title{
Gaining and losing stream reaches have opposite hydraulic conductivity distribution patterns
}

\author{
X. Chen ${ }^{1}$, W. Dong ${ }^{1,2}$, G. Ou ${ }^{1}$, Z. Wang ${ }^{1}$, and C. Liu ${ }^{1}$ \\ ${ }^{1}$ School of Natural Resources, University of Nebraska-Lincoln, Lincoln, NE 68583-0996, USA \\ ${ }^{2}$ Key Laboratory of Groundwater Resources and Environment of China Ministry of Education, Jilin University, \\ Changchun, 130021, China
}

Correspondence to: X. Chen (xchen2@unl.edu)

Received: 16 November 2012 - Published in Hydrol. Earth Syst. Sci. Discuss.: 4 February 2013

Revised: 24 May 2013 - Accepted: 31 May 2013 - Published: 9 July 2013

\begin{abstract}
In gaining streams, groundwater seeps out into the streams. In losing streams, stream water moves into groundwater systems. The flow moving through the streambed sediments under these two types of hydrologic conditions is generally in opposite directions (upward vs. downward). The two opposite flow mechanisms affect the pore size and fine particle content of streambeds. Thus it is very likely that the opposite flow conditions affect the streambed hydraulic conductivity. However, comparisons of the hydraulic conductivity $(K)$ of streambeds for losing and gaining streams are not well documented. In this study, we examined the $K$ distribution patterns of sediments below the channel surface or stream banks for the Platte River and its tributaries in Nebraska, USA. Two contrasting vertical distribution patterns were observed from the test sites. In gaining reaches, hydraulic conductivity of the streambed decreased with the depth of the sediment cores. In losing reaches, hydraulic conductivity increased with the depth of the sediment cores. These contrasting patterns in the two types of streams were mostly attributed to flow directions during stream water and groundwater exchanges. In losing reaches, downward movement of water brought fine particle into the otherwise coarse sediment matrix, partially silting the pores. For gaining reaches, upward flow winnowed fine particles, increasing the pore spacing in the top parts of streambeds, leading to higher hydraulic conductivity in shallower parts of streambeds. These flux directions can impact $K$ values to depths of greater than $5 \mathrm{~m}$. At each study site, in situ permeameter tests were conducted to measure the $K$ values of the shallow streambed layer. Statistical analyses indicated that $K$ values from the sites of losing
\end{abstract}

reaches were significantly different from the $K$ values from the sites of gaining reaches.

\section{Introduction}

Stream networks drain land surface runoff and can receive groundwater baseflow. In stream-aquifer interactions, water or solute passes through streambeds that control the hydrologic connectivity between stream water and groundwater. Streambed hydraulic conductivity is a key parameter in the analysis of stream-aquifer interactions. In areas where streamflow depletion induced by groundwater use is a water management issue, knowledge of streambed hydraulic conductivity is needed in the development of integrated water use plans of stream water and groundwater. When rivers are polluted, migration of pollutants from rivers to the adjacent aquifer systems poses a big threat to the quality of the groundwater supply systems and thus to human health. Streambed hydraulic properties control the seepage velocity and thus the movement of contaminants between rivers and groundwater.

Bank filtration processes are associated with downward flow in streambeds and can concentrate fine particulate matter that clogs streambeds (Schubert, 2002). Upwelling flow in streambeds on the other hand enlarges sediment pore size and enhances streambed hydraulic conductivity (Song et al., 2007). Laboratory experiments indicated that seepage direction at the water-sediment interface of a hyporheic setting affects the magnitude of sediment hydraulic conductivity $(K)$ 
(Rosenberry and Pitlick, 2009a). When streambed mobility is low, upward flow enhances the hydraulic conductivity and downward flow reduces hydraulic conductivity. The ratio of $K$ determined during upward flow to $K$ determined during downward flow is greater than 1 and can be as high as 2.4 (Rosenberry and Pitlick, 2009a). Downward seepage pulls fine-grained particles onto or into the bed until they clog pore spaces and reduce $K$ in the sediment volume at or just below the sediment-water interface (Rosenberry and Pitlick, 2009a). Upward seepage velocity at the points of preferential discharge often is sufficient to suspend particles, even with no surface water current. The upward force thus expands the pore space, leading to higher hydraulic conductivity.

Some lab flume studies (Packman et al., 2000a,b) demonstrated that the forming of clogging layers is a common sedimentation process in streams. Clogging is a very effective process that reduces streambed hydraulic conductivity. The simulations using flumes often neglect the groundwater component and do not relate seepage direction to $K$ changes. A recent study by Karwan and Saiers (2012) suggested that clay-sized particles and colloids can travel within the pore space of sediments by stream water filtration in the hyporheic zone. Steady dynamic pressure variations over bedforms induce streamflow to enter the streambed and then exit (Elliot and Brooks, 1997). While they did not discuss the possible effect of this filtration on $K$, it is apparent that when retention of clay takes place in the streambed, the fine materials will likely reduce the hydraulic conductivity. This numerical simulation of particle transport in sediments (Karwan and Saiers, 2012) focuses on the filtration of clay particles in small-scale sediments ( $<0.5 \mathrm{~m}$ in depth) below the watersediment interface. Laboratory studies are conditioned to a small sand column or sand box. Thus, these small-scale studies under controlled hydrodynamic conditions do not fully reflect how the streambed hydraulic conductivity has been changed by upward or downward flow directions in the sediments under natural settings of streambeds. Rosenberry and Pitlick (2009a) suggested that it would be valuable if researchers could document the effects of seepage direction (upward or downward) on the $K$ distribution in the natural world because this directional bias has been neglected in most field investigations. In a field investigation in the South Platte River of Colorado using a seepage meter method, Rosenberry and Pitlick (2009b) confirmed that vertical hydraulic conductivity at specific locations varied depending on seepage direction, and was slightly larger to more than an order of magnitude larger during upward seepage than during downward seepage.

An infiltration situation in losing streams can occur under natural conditions or be induced by lowering the groundwater table by adjacent pumping wells (Hiscock and Grischek, 2002). Streambeds and the river banks provide filtration functions that lead to deposition of fine particulate matter (organic or inorganic), biological colonization, and chemical precipitation or mineralization. The input and deposition of sediment particles, micro-organisms and colloids, and the precipitation of iron and manganese oxy-hydroxides and calcium carbonates within the streambed reduce streambed hydraulic conductivity (Hiscock and Grischek, 2002). The physical, biological and chemical processes are the driving mechanisms that clog stream sediments and reduce the sediment pores under losing conditions (Hancock, 2002). The physical process mainly involves settling of fine particulate matter on the water-sediment interface; some fine particles can be transported into the pores of the upper streambed layer depending on the hydrologic condition and sediment structures (Bouwer, 2002; Cui et al., 2008; Stuyfzand et al., 2006; Wett et al., 2002). For example, the accumulation of fine solids at a Rhine River riverbank filtration site is limited to the water-sediment interface, and chemical precipitation occurs about $10 \mathrm{~cm}$ below the interface (Schubert, 2002). Gunkel and Hoffmann (2006) confirmed that in a bank filtration system of Lake Tegel (Germany) algae (mainly diatoms) adapts to the sediment pore system and has a very high concentration in the upper $5 \mathrm{~cm}$ of sediment which significantly influences the composition of the upper sediment layer. The concentration of algae rapidly decreases below $10 \mathrm{~cm}$. It seems that the effect of the physical, biological and chemical clogging is most significant only at a small depth. However, the clogging can reduce the streambed hydraulic conductivity by 10-100 times and thus reduces the hydrological connections between streams and the adjacent aquifers. The filtration efficiency of the streambed depends on several physical, biological and chemical factors, including the size of suspended particles and streambed sediment composition, pore water velocity, pore water $\mathrm{pH}$ and ionic strength, and the surface chemical composition of the suspended particles (Ren and Packman, 2002; Karwan and Saiers, 2012). Differences in grain size (and therefore pore size) of the framework exercises a strong controlling influence on the infiltration of fine particles into bed interstices (Frostick et al., 1984).

Numerical simulations of stream-groundwater interactions across channels indicate that stream water infiltration in streambeds can penetrate a depth greater than one meter and reach a depth of up to $5 \mathrm{~m}$ beneath the water-sediment interface (Chen and Chen, 2003). Numerical simulations of hyporheic exchanges along stream longitudinal profiles indicate that stream water penetration into streambeds can reach depths up to $10 \mathrm{~m}$ (Gooseff et al., 2006). This filtration process, if bringing fine particles into the channel sediments, will reduce the pore space of the original framework of the streambed, leading to decreased streambed $K$ at greater depths than laboratory experiments can illustrate. However, the effective depth of this potential mechanism for reducing $K$ has not been confirmed through field investigation due to the difficulties of measuring streambed hydraulic conductivities for larger depths. When water particles travel through the original coarse streambed, more fine particles are likely retained in the upper part of the streambed and the concentration of suspended fine particles in the flow reduces gradually 
as the infiltrated stream water plume travels downward. Consequently, this filtration process can form a streambed that has a higher content of silt and clay in the shallow parts of the streambed. It will thus be interesting to investigate how this filtration process affects $K$ variations with depth in losing stream reaches. Furthermore, in losing streams, water moves laterally in addition to seeping downward as shown by Chen and Chen (2003). Thus, fine particles can filtrate laterally into the sediments below river banks. Field observations by Banzhaf et al. (2011) and Gerecht et al. (2011) indicated that stream water is able to move into river banks laterally for several meters. To the best of our knowledge, careful analysis of $K$ profiles specifically for losing streams has not been conducted.

Opposite to losing streams, gaining streams receive groundwater which migrates predominantly in the vertical direction beneath the water-sediment interface. This upward movement expands pore size and then enhances $K$ of the top parts of streambeds (Song et al., 2007; Chen, 2011). Upward flow can pick up fine particles that otherwise are retained on the surface of coarse particles or clog between coarse grains. The water flow in pores suspends the fine particles and brings them upwards into streams; stream currents wash away the fine materials. This winnowing process sorts streambed sediments and leaves coarse materials in streambeds. As a result, the hydraulic conductivity becomes larger in the top layer of streambeds (Dong et al., 2012).

Based on the above analyses, the $K$ distribution in these two groups of streams will form opposite patterns. It is likely that in losing reaches, streambed $K$ is the smallest near the water-sediment interface and increases with depth; in gaining streams, streambed $K$ is likely the greatest near the water-sediment interface and decreases with depth. It would be ideal if a study were conducted in the same stream reach during a losing condition and a gaining condition. It is difficult, however, to predict when the change of seepage direction will occur or whether the direction will change for a given stream segment. In this study, we selected several stream reaches which were either predominantly losing or predominantly gaining. We determined the losing and gaining conditions for the study sites based on field methods or groundwater modeling results. We conducted in-channel falling-head permeameter tests to determine the $K$ for the top streambed layers using the method described by Chen (2004) and Genereux et al. (2008). From these $K$ values, we identified the difference of the $K$ of the top-layer sediments between the two types of streams. We then collected a sequence of cores from sediments below the top layer to a depth of about 10 to $15 \mathrm{~m}$ and determined $K$ for these cores. From the $K$ profiles with depth, we analyzed the distribution trend of $K$ with depth for these two types of streams.

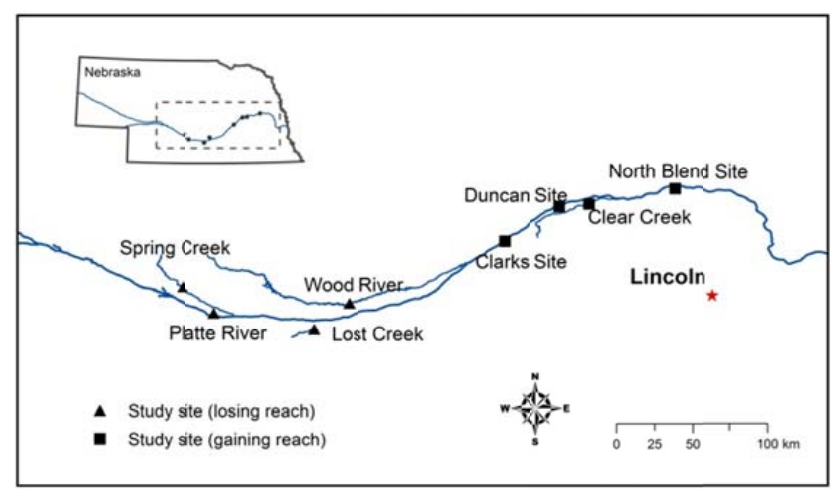

Fig. 1. Location map of eight study sites in south-central and eastern Nebraska. Four study sites were in gaining stream reaches and the other four study sites were in losing stream reaches.

\section{Study area and methods}

\subsection{Study area}

The study area is in the Platte River valley of south-central and eastern Nebraska, USA. The Platte River flows from west to east of Nebraska and joins the Missouri River at the eastern border of Nebraska. The Platte River and its tributaries in the study area have generally good connections with the High Plains aquifer. Extensive groundwater irrigation in the past $60 \mathrm{yr}$ and projected climate changes make integrated management of groundwater and stream water a necessary policy. In south-central Nebraska, some reaches of the river network lose water to the aquifer but other reaches gain water from the aquifer. In this study, eight study sites were selected along the Platte River and its tributaries. Four study sites were located in south-central Nebraska, including one site on the Platte River, and one site on each of the three tributaries: Spring Creek, Lost Creek, and Wood River. These four sites were under losing conditions. Field investigations of the four sites were performed in July and August of 2011. The other four study sites were located in eastern Nebraska. Three sites were on the Platte River and they were near Clarks, Duncan and North Bend. Results from two groundwater flow models indicated that these three sites were in gaining reaches (Wang, 2008; Chen and Ou, 2013). The fourth site was in Clear Creek, a tributary of the Platte River. The Clear Creek site was determined to be in a gaining reach using temperature and hydraulic head data (Dong et al., 2012). The field investigations for these sites were conducted between 2005 and 2012. The sediments in the Platte River consist mainly of sand and gravel. The regional groundwater flows from west to east. Figure 1 shows the eight study sites. 


\subsection{Determination of losing and gaining conditions}

Stream water and groundwater temperatures were measured using the Multi-Parameter Testr 35 at four study sites during our field work (the Lost Creek, the Wood River, the Platte River north channel, and the Clear Creek sites). Groundwater temperature here refers to the temperature measured from sediments about 40 to $50 \mathrm{~cm}$ beneath the water-sediment interface. For a losing reach, the temperatures of stream water and groundwater will be close to each other because stream water infiltrates into the underlying streambed and into the sediments on both sides of the channel, although there will be a time delay of sediment temperature to peak temperature in stream water (Silliman et al., 1995). For gaining streams, the water temperature beneath the water-sediment interface is close to the shallow regional groundwater temperature and the stream water temperature is higher because of the high atmospheric temperatures in the summer. At the Spring Creek site, stream water and air temperatures were measured. The streambed temperature was not measured. During the field test, the stream water at this site was muddy and deep. The temperature device was not operable for measuring streambed temperature. We measured the hydraulic head of the streambed and it was lower than the stream stage, indicating a losing condition. For the three study sites in the eastern Platte River (the sites near Clarks, Duncan and North Bend), we used the results of two groundwater flow models (Wang, 2008; Chen and Ou, 2013) to determine the gaining conditions. Wang (2008) and Chen and Ou (2013) modeled the hydrologic interactions between the Platte River and the aquifer and calculated the baseflow the Platte River received from the aquifer for a period longer than $50 \mathrm{yr}$.

\subsection{Permeameter tests for the streambeds}

In this study, an in situ permeameter test method was used to determine the vertical hydraulic conductivity $K_{\mathrm{v}}$ of the top layer of streambed at each site. This in situ method used open-ended tubes to measure the declining rate of water inside the tube when the water passed through the streambed. This in situ permeameter test is a cost effective method and can be conveniently operated in river channels to determine $K_{\mathrm{V}}$ values of streambeds while the sedimentary structures of the tested sediments are very little disturbed. The in situ permeameter test procedures are well documented by Chen (2004) and Genereux et al. (2008). For most of the study sites, 8 to 12 in situ permeameter tests were conducted to determine the $K_{\mathrm{v}}$ values of the top layer of streambed.

\subsection{Sediment coring}

We used a Geoprobe direct-push machine to collect sediment cores from the study sites. The Geoprobe direct-push machine has two functions. The first function is that it can generate an electrical conductivity (EC) $\log$ of sediments. The EC values of silt and clay layers are one or two times greater than the EC values of sand and gravel layers due to their difference in mineral composition. Therefore, an EC log can provide the vertical pattern of hydrostratigraphic units very well. During EC logging, a probe was pushed through sediments without the need of a borehole. Thus, this EC logging procedure had a small disturbance to the sediments surrounding the probe. A laptop computer was connected to the Geoprobe system during the logging process and displayed the EC log of the tested streambed on site. The EC logs clearly show the interbedded patterns of coarse sediments (medium-coarse sand and gravel) and fine sediments (fine sand and silt/clay).

The second function is that the Geoprobe generates continual sequences of sediment cores. Unconsolidated sediments were sampled into a $1.5 \mathrm{~m}$ long tube when the sampler was driven through the streambeds. The coring tube was transparent. After the core was brought to the ground surface, the lithological patterns of the streambed sediments were examined at test sites and were cross-checked with the patterns of EC logs. At the study sites, the Geoprobe machine got into the river channel when the access was permitted. Otherwise, coring was conducted at the river banks. At each test site, the first core was collected for the depth of $\sim 0-1.5 \mathrm{~m}$; the second core was collected from the depth of $\sim 1.5-3 \mathrm{~m}$. Repeating the sampling procedure gave a continual sequence of sediment cores. At each test site, an EC log was produced before sediment coring. The EC logging spot and the coring spot were about one meter apart. Chen et al. (2008) provided details of using Geoprobe for EC logging and sediment coring. The sediment cores from the Wood River, Spring Creek, and Clear Creek sites were collected from the bank, about $1 \mathrm{~m}$ from the waterline at these test sites. The sediment cores from the other five sites were collected from the river channel. These cores were transported back to the laboratory for conducting falling-head permeameter tests. The in-lab permeameter test method determined $K_{\mathrm{v}}$ values of these sediment cores from each of the study sites. During the test, the sediments were not repacked and the original sedimentary structure was preserved. The in-lab permeameter test method for determining the $K_{\mathrm{v}}$ values of sediment cores was described by Chen et al. (2008). After the $K$ values of the cores were determined, $K$ profiles with depth were plotted.

\section{Results}

\subsection{Temperature and EC values in stream water and groundwater}

The sediment temperatures for four study sites and stream water temperatures for five study sites are shown in Table 1. The sediment temperature was $16^{\circ} \mathrm{C}$ in Clear Creek, measured in August 2011, whereas the stream water temperature was $22.3^{\circ} \mathrm{C}$ (see Table 1). The regional groundwater temperature was about $12-15^{\circ} \mathrm{C}$ in this area. The sediment 
Table 1. Temperatures and EC values collected from five study sites.

\begin{tabular}{|c|c|c|c|c|c|c|}
\hline \multirow{2}{*}{$\begin{array}{l}\text { Test } \\
\text { site }\end{array}$} & \multicolumn{3}{|c|}{ Temperature ${ }^{\circ} \mathrm{C}$} & \multirow[b]{2}{*}{ Air } & \multicolumn{2}{|c|}{$\mathrm{EC} \mu \mathrm{s} \mathrm{cm}^{-1}$} \\
\hline & $\begin{array}{l}\text { Streambed } \\
\text { sediments }\end{array}$ & $\begin{array}{l}\text { Stream } \\
\text { water }\end{array}$ & & & $\begin{array}{r}\text { Stream } \\
\text { water }\end{array}$ & $\begin{array}{c}\text { Ground } \\
\text { water }\end{array}$ \\
\hline Clear Creek & 16 & 22.3 & 28.5 & & 637 & 312 \\
\hline Spring Creek & NA & 22.9 & 26.5 & & 979 & NA \\
\hline Lost Creek & 25.5 & 25.4 & 31.5 & & 976 & 384 \\
\hline Wood River & 23.6 & 24 & 33.1 & & 1360 & 546 \\
\hline $\begin{array}{l}\text { Platte River } \\
\text { north channel }\end{array}$ & 26.8 & 28.9 & 34.5 & & 824 & 356 \\
\hline
\end{tabular}

temperature in Clear Creek was close to the ground water temperature. Thus, Clear Creek was determined to be a gaining stream. The sediment temperatures in Wood River, Platte River north channel, and Lost Creek were greater than $20^{\circ} \mathrm{C}$ and close to the stream water temperature (Table 1). They were determined to be losing streams.

The Multi-Parameter Testr 35 was also used to measure the electrical conductivity of the stream water at these study sites. The EC values of stream water were higher than those of groundwater at the four study sites (Table 1). The EC values in stream water ranged from 637 to $1360 \mu \mathrm{sm}^{-1}$, whereas those in groundwater ranged from 312 to $546 \mu \mathrm{sm}^{-1}$ (see Table 1). The EC value of the stream water for the Clear Creek site (in a gaining reach) was $637 \mu \mathrm{cm}^{-1}$, and it was lower compared to the EC values of $824-1360 \mu \mathrm{s} \mathrm{cm}^{-1}$ for the four sites in losing reaches.

\section{2 $K_{\mathrm{v}}$ for the top layer of streambeds in losing streams}

Streambeds in losing stream reaches often have higher contents of fine-grained materials (silt/clay and fine sand) that fill the interstices of coarse-grained sediments (medium-coarse sand and gravel). This can lead to poorly sorted sediments and lower hydraulic conductivities. Visual examination of the sediments reveals the mixed nature of sand/gravel and finegrained materials. At the Wood River site and the Platte River north channel site, patches of fine-grained sediments, as well as poorly sorted sand and gravel, were observed. These lower permeability silt/clay and fine-sand lenses exist in the channel surface but have not formed a continuous clogging layer. The mixture of the fine-grained sediments with the coarse sediments (medium sand, coarse sand and gravel) is reflected by a wide range of streambed hydraulic conductivities. For example, at the Wood River test site, ten in situ permeameter tests were conducted. Four tests encountered silt/clay and fine sand and their $K_{\mathrm{v}}$ values are smaller than $0.6 \mathrm{~m} \mathrm{~d}^{-1}$. The other six tests were conducted in medium-coarse sand and gravel, and their $K_{\mathrm{v}}$ values ranged from 1.4 to $17.1 \mathrm{~m} \mathrm{~d}^{-1}$, indicating permeable sediments. Table 2 lists the minimum, maximum, and median $K_{\mathrm{V}}$ values for the study site. Figure 2 is the box plot showing the distribution of the $K_{\mathrm{v}}$ values. The $K_{\mathrm{v}}$ values fall in six orders of magnitude.
Table 2. Maximum, minimum, and median values of $K_{\mathrm{V}}$ from the in situ permeameter tests.

\begin{tabular}{llll}
\hline \multirow{2}{*}{ Test } & \multicolumn{3}{c}{$K_{\mathrm{V}}$ values $\left(\mathrm{m} \mathrm{d}^{-1}\right)$} \\
\cline { 2 - 4 } site & Minimum & Maximum & Median \\
\hline Wood River & 0.0003 & 17.1 & 1.5 \\
$\begin{array}{l}\text { Platte River (P. R.) } \\
\text { north channel }\end{array}$ & 0.051 & 25.9 & 1.6 \\
Lost Creek & 0.0003 & 0.48 & 0.11 \\
Spring Creek & 0.018 & 0.2 & 0.048 \\
Clear Creek & 1.2 & 110.8 & 16.6 \\
P. R. North Bend & 22.4 & 50.9 & 31.8 \\
$\begin{array}{l}\text { P. R. Clarks } \\
\text { P. R. Duncan }\end{array}$ & 14.9 & 60.3 & 26.5 \\
\hline
\end{tabular}

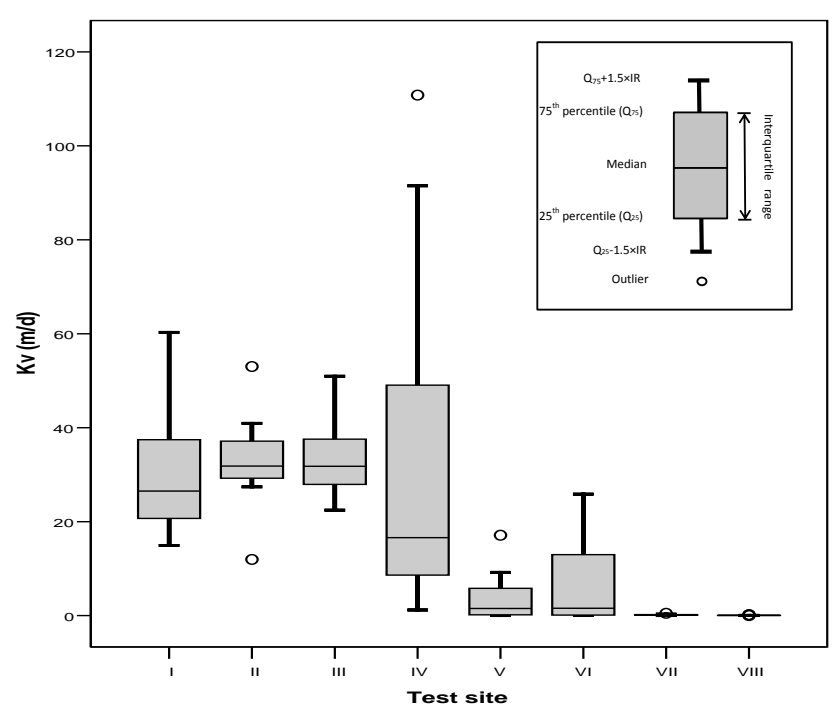

Fig. 2. Box plot to show the $K_{\mathrm{V}}$ distribution for the eight test sites. The label on the horizontal axis is designated as follows: I = Platte River-Clarks, II = Platte River-Duncan, III = Platte RiverNorth Bend, IV = Clear Creek; V = Wood River, VI= Platte River north channel, VII $=$ Lost Creek, VIII = Spring Creek.

At the Platte River north channel site, five of ten tests encountered a mixture of fine-grained and coarse-grained sediments and had $K_{\mathrm{v}}$ values from 0.05 to $0.56 \mathrm{~m} \mathrm{~d}^{-1}$. The other five tests gave $K_{\mathrm{v}}$ values from 2.5 to $25.9 \mathrm{~m} \mathrm{~d}^{-1}$, indicating high permeability sediments (sand and gravel). The $K_{\mathrm{v}}$ values fall in four orders of magnitude. The minimum, maximum and median $K_{\mathrm{v}}$ values are listed in Table 2 . The distribution of the $K_{\mathrm{v}}$ from this site is similar to the pattern for the Wood River site (Fig. 2). The Platte River at the study site is braided and the channel sediments consist mainly of sand and gravel. The width of the north channel where we conducted this study was about $30 \mathrm{~m}$. The average water depth for the 10 permeameter test spots was $25.6 \mathrm{~cm}$. One sediment sample was taken from a permeameter test point $\left(K_{\mathrm{v}}=25.9 \mathrm{~m} \mathrm{~d}^{-1}\right)$ at the Platte River north channel site and 
was sieved for grain size analysis. This sample contained $21.2 \%$ fine sand and $1.8 \%$ silt/clay; the rest was medium to coarse sand and gravel. The content of fine particles in this sample was higher than that for samples from the Platte River in the gaining sites (see the results in Sect. 3.3).

The streambeds at the other two sites of losing streams in south-central Nebraska (Lost Creek and Spring Creek) were nearly fully clogged. When the channel is fully silted, a layer of fine-grained sediments covers the channel surface. The $K_{\mathrm{v}}$ values determined from 10 in situ permeameter tests in Lost Creek ranged from 0.0003 to $0.48 \mathrm{~m} \mathrm{~d}^{-1}$ with a median of $0.12 \mathrm{~m} \mathrm{~d}^{-1}$. A sediment sample was taken from the spot of a permeameter test in Lost Creek, and the sample was sieved for grain size analysis. This sample consisted of $56.8 \%$ fine sand and $4 \%$ silt/clay. A sample from another test point contained $85.8 \%$ fine sand and $5.5 \%$ silt/clay. This large amount of fine-grained sediments was consistent with the lower permeability of this streambed.

At the Spring Creek site, the $K_{\mathrm{v}}$ values ranged from 0.018 to $0.2 \mathrm{~m} \mathrm{~d}^{-1}$, with a median value of $0.048 \mathrm{~m} \mathrm{~d}^{-1}$ (Table 2). Generally, when $K_{\mathrm{v}}$ values are smaller than $0.1 \mathrm{~m} \mathrm{~d}^{-1}$, sediments are not very permeable. At the Wood River and the Platte River north channel sites, $11 K_{\mathrm{v}}$ values are greater than $1 \mathrm{~m} \mathrm{~d}^{-1}$; at the Lost Creek and Spring Creek sites, all of the $K_{\mathrm{V}}$ values are smaller than $1 \mathrm{~m} \mathrm{~d}^{-1}$. The distribution patterns of $K_{\mathrm{v}}$ for the Lost Creek and Spring Creek sites are similar to each other (see Fig. 2), but differ from the pattern of $K_{\mathrm{V}}$ for the other two losing stream sites.

\section{3 $K_{\mathrm{v}}$ for the top layer of streambeds in gaining streams}

In contrast, the gaining stream reaches have well sorted and clean sand and gravel in the top layer of streambeds with very small amounts of silt and clay $(<1 \%)$. According to Dong et al. (2012), the weight percentage of silt and clay particles $(<0.0625 \mathrm{~mm})$ in 14 sediment samples from the Clear Creek site ranged from 0.1 to $1.9 \%$ with an average of $0.6 \%$. These types of sediments often have hydraulic conductivity values greater than $1 \mathrm{~m} \mathrm{~d}^{-1}$. For example, in Clear Creek, the $K_{\mathrm{v}}$ values determined from 12 in situ permeameter tests in the streambed in 2010 ranged from 1.2 to $110.7 \mathrm{~m} \mathrm{~d}^{-1}$ with a median of $16.6 \mathrm{~m} \mathrm{~d}^{-1}$. At the site to the west of North Bend, a total of 48 in situ permeameter tests were conducted in 2008 in a 6 by 8 grid with grid spacing of $1.5 \mathrm{~m}$. The $K_{\mathrm{v}}$ ranged from 22.5 to $50.9 \mathrm{~m} \mathrm{~d}^{-1}$, with an average value of $33.3 \mathrm{~m} \mathrm{~d}^{-1}$ (a median value of $31.8 \mathrm{~m} \mathrm{~d}^{-1}$ ). None of the $K_{\mathrm{v}}$ values were smaller than $1 \mathrm{~m} \mathrm{~d}^{-1}$. Eleven in situ permeameter tests were conducted in the Platte River at the Clarks site, and Fig. 2 shows the distribution of these $K_{\mathrm{v}}$ values. The $K_{\mathrm{v}}$ values ranged from 14.9 to $61.3 \mathrm{~m} \mathrm{~d}^{-1}$ with an average of $31.3 \mathrm{~m} \mathrm{~d}^{-1}$. A sediment sample was collected after each of the 11 permeameter tests was conducted. Sieving analysis results indicated that the sediments contained trace amounts of silt and clay $(<0.2 \%)$ and a small amount of fine sand ranging from 1.4 to $12.4 \%$ with an average of $6 \%$. The rest of these sediment samples consisted of medium and coarse sand and some gravel. Fifteen in situ permeameter tests were conducted in the Platte River near Duncan. The $K_{\mathrm{v}}$ values ranged from 11.9 to $53.0 \mathrm{~m} \mathrm{~d}^{-1}$ with an average of $33.0 \mathrm{~m} \mathrm{~d}^{-1}$. Figure 2 shows the distribution of these $K_{\mathrm{v}}$ values. Sieving analysis of the sediment samples from the 15 test spots indicated that the streambed contained fine sand ranging from 2.1 to $12.1 \%$ with an average of $4.9 \%$ and had trace amounts of silt and clay (compared to $22.2 \%$ fine sand and $1.8 \%$ silt/clay for the sample in the Platte River north channel site under losing conditions). The rest of these sediment samples contained medium and coarse sand and some gravel. As one can see from these measurements, the $K_{\mathrm{v}}$ measurements from the gaining streams had a very narrow range of distribution with high values. Note that the median $K_{\mathrm{v}}$ value for the Platte River north site (losing condition) was only $1.6 \mathrm{~m} \mathrm{~d}^{-1}$. Comparing to the median $K_{\mathrm{v}}$ values at the Lost Creek and Spring Creek sites, the median $K_{\mathrm{v}}$ values in the four gaining condition sites were greater by 3 to 4 orders of magnitude.

The $K_{\mathrm{v}}$ patterns for the four gaining stream sites, as shown in the box plot of Fig. 2, are very similar to each other, particularly for the three sites from the Platte River (Clarks, Duncan, and west of North Bend). The $K_{\mathrm{v}}$ patterns for the four gaining stream sites differ very much from the patterns for the four losing stream sites.

The Kruskal-Wallis test was used to determine whether the $K_{\mathrm{v}}$ values from any two test sites belong to the same population. This analysis was performed using the statistical function in MATLAB. For this statistical analysis, the null hypothesis was that all samples were drawn from the same population, and the program returned $p$ values. If the $p$ value was near zero, it rejected the hypothesis and indicated that at least the median value of one group of $K_{\mathrm{v}}$ values was significantly different from the other. When $p>0.05$ (or at the confidence level of $95 \%$ ), it accepted the null hypothesis that the two sets of $K_{\mathrm{v}}$ values were drawn from the same population. The $p$ values for the Kruskal-Wallis test are summarized in Table 3.

These $p$ values indicate that $K_{\mathrm{v}}$ from any test site of the gaining streams differ from $K_{\mathrm{v}}$ from any single site of the losing streams. In the four gaining stream sites, the $K_{\mathrm{v}}$ values were drawn from the same population. Among the four losing stream sites, the $K_{\mathrm{v}}$ values from the Lost Creek and Spring Creek sites were drawn from the same population; the $K_{\mathrm{v}}$ values from the Wood River and Platte River north channel sites were drawn from the same population. However, $K_{\mathrm{V}}$ values from the former two sites statistically differ from the $K_{\mathrm{v}}$ values of the latter two sites. Although the four sites were under losing conditions, the Lost Creek and Spring Creek sites had higher levels of siltation. The statistical results are consistent with the streambed hydraulic conditions. 
Table 3. $p$ values from the Kruskal-Wallis test for comparison of the similarity of $K_{\mathrm{V}}$ values between two test sites. When $p$ value is $>0.05$, the similarity is statistically significant.

\begin{tabular}{llllllllllllll}
\hline $\begin{array}{l}\text { Site } \\
\text { pair* }\end{array}$ & $\begin{array}{l}p \\
\text { value }\end{array}$ & $\begin{array}{l}\text { Site } \\
\text { pair }\end{array}$ & $\begin{array}{l}p \\
\text { value }\end{array}$ & $\begin{array}{l}\text { Site } \\
\text { pair }\end{array}$ & $\begin{array}{l}p \\
\text { value }\end{array}$ & $\begin{array}{l}\text { Site } \\
\text { pair }\end{array}$ & $\begin{array}{l}p \\
\text { value }\end{array}$ & $\begin{array}{l}\text { Site } \\
\text { pair }\end{array}$ & $\begin{array}{l}p \\
\text { value }\end{array}$ & $\begin{array}{l}\text { Site } \\
\text { pair }\end{array}$ & $\begin{array}{l}p \\
\text { value }\end{array}$ & $\begin{array}{l}\text { Site } \\
\text { pair }\end{array}$ & $\begin{array}{l}p \\
\text { value }\end{array}$ \\
\hline I-II & 0.392 & II-III & 0.784 & III-IV & 0.171 & IV-V & 0.004 & V-VI & 0.082 & VI-VII & 0.034 & VII-VIII & 0.066 \\
I-III & 0.179 & II-IV & 0.329 & III-V & 0 & IV-VI & 0.012 & V-VII & 0.028 & VI-VIII & 0.004 & \\
I-IV & 0.325 & II-V & 0 & III-VI & 0 & IV-VII & 0 & V-VIII & 0.007 & & & & \\
I-V & 0 & II-VI & 0 & III-VII & 0 & IV-VIII & 0 & & & & & \\
I-VI & 0.001 & II-VII & 0 & III-VIII & 0 & & & & & & & \\
I-VII & 0 & II-VIII & 0 & & & & & & & & & \\
I-VIII & 0 & & & & & & & & & & \\
\hline
\end{tabular}

* I = Platte River-Clarks, II = Platte River-Duncan, III = Platte River-North Bend, IV = Clear Creek; V = Wood River, VI= Platte River north channel, VII = Lost Creek, VIII = Spring Creek.
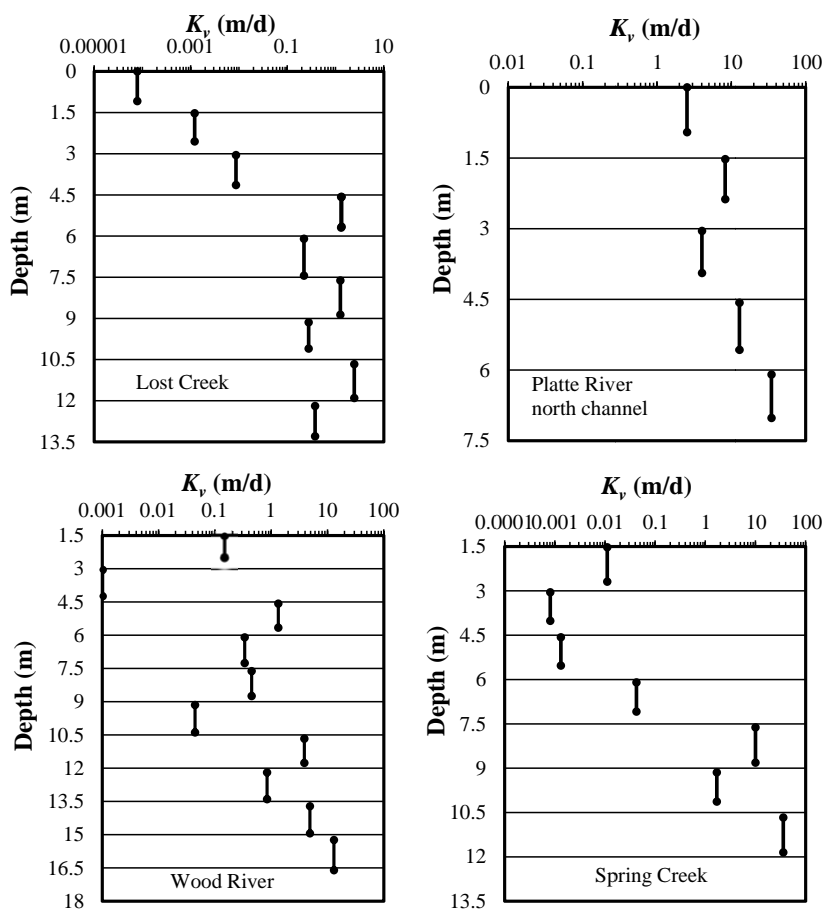

Fig. 3. Distribution of $K_{\mathrm{V}}$ with depth in losing streams for four study sites in the Platte River north channel, Wood River, Spring Creek, and Lost Creek of south-central Nebraska.

\section{4 $\quad K_{\mathrm{v}}$ profiles for losing streams}

$K_{\mathrm{v}}$ determined from each sediment core generated by the Geoprobe was plotted vs. depth. Thus, one $K_{\mathrm{v}}$ profile was produced for each test site. Figure 3 shows the $K_{\mathrm{v}}$ profiles for the four losing stream sites in south-central Nebraska. All of the $K_{\mathrm{v}}$ profiles show an increasing trend with depth (Fig. 3). In Lost Creek, the streambed sediment at the depth interval of $\sim 0-1.5 \mathrm{~m}$ has a low $K_{\mathrm{v}}$ value of $0.00008 \mathrm{~m} \mathrm{~d}^{-1}$, and the $K_{\mathrm{v}}$ values increase to 0.0012 and $0.09 \mathrm{~m} \mathrm{~d}^{-1}$ in the next two depth intervals. The five $K_{\mathrm{v}}$ values below the depth of $4.5 \mathrm{~m}$ fluctuate in a constant range, and they do not show an increasing or decreasing trend. We interpret that the filtration of fine particles reached a depth of about $4.5 \mathrm{~m}$ in this small creek. The surface water width across Lost Creek was about $2.7 \mathrm{~m}$ in July 2011 during the field work, and the water depth was only $15 \mathrm{~cm}$. These cores were taken from the channel.

At the Platte River north channel site, the five $K_{\mathrm{v}}$ values show an increasing trend with the depth. These five cores were taken from the unconsolidated sediments. The sediments beneath the depth of $7.5 \mathrm{~m}$ are an aquitard that is extensively distributed in this region and separates the unconsolidated Quaternary sediments from the Tertiary Ogallala Group (Chen et al., 2008). Compared to Lost Creek, the overall $K_{\mathrm{v}}$ values in the Platte River are much greater, but the decreasing trend is the same at the two sites.

For the Wood River and Spring Creek sites, the Geoprobe coring was conducted on the river banks. The river banks were about 1 to $1.5 \mathrm{~m}$ above the water. Thus, the first sediment cores at the two sites were collected from unsaturated bank material, and the $K_{\mathrm{v}}$ values for the two cores were not included for the analysis. The two $K_{\mathrm{v}}$ profiles at the Wood River and Spring Creek sites show increasing trends. For the Wood River site, an increasing trend is shown for the depth of 1.5 to $16.5 \mathrm{~m}$. The channel width and water depth were 6.9 and $16 \mathrm{~cm}$, respectively. An increasing trend of $K_{\mathrm{v}}$ with depth is also clear at the Spring Creek site (Fig. 3). The channel width and water depth were 4.6 and $74 \mathrm{~cm}$, respectively.

For each of the four test sites, the $K_{\mathrm{v}}$ values for the top five sediment cores already indicate a decreasing trend with depth. Table 4 summarizes the minimum, maximum, and median $K_{\mathrm{V}}$ values for the top five cores. The minimum and median values for the Wood River, Lost Creek and Spring Creek sites are all smaller than $0.5 \mathrm{~m} \mathrm{~d}^{-1}$, indicating lowpermeability sediments. The minimum and median values from the Platte River north channel site are much higher. This suggests that in permeable streambeds, a decreasing trend of $K_{\mathrm{V}}$ with depth can still form when the stream is under losing conditions. 

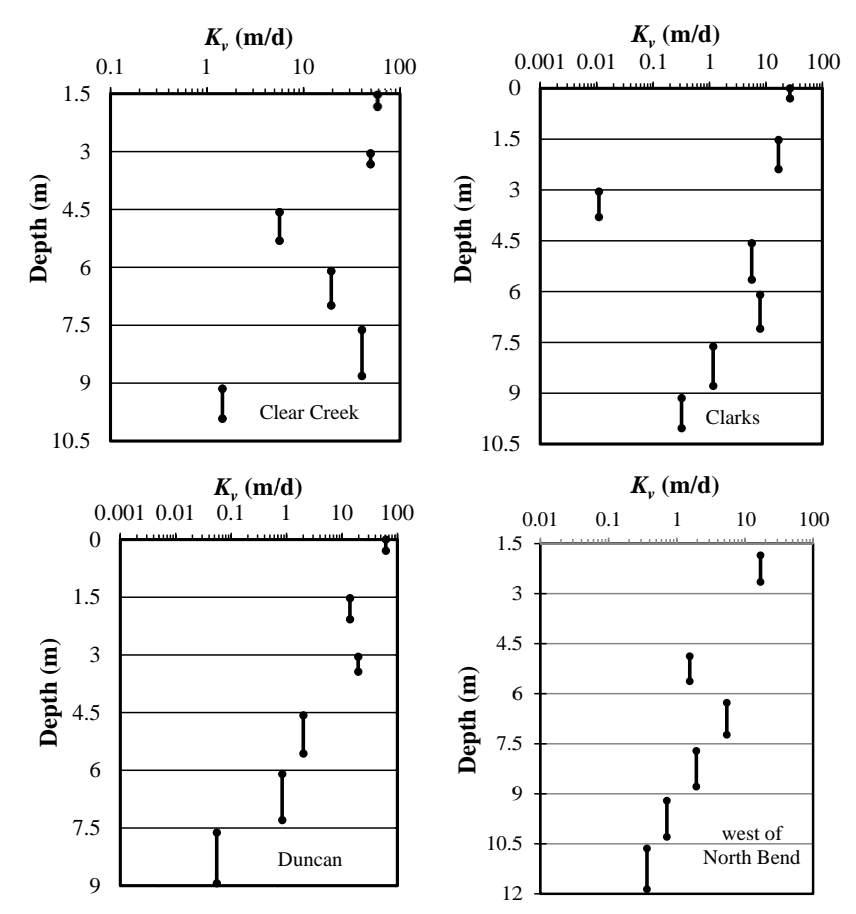

Fig. 4. Distribution of $K_{\mathrm{V}}$ with depth in gaining streams for four study sites in eastern Nebraska. Three study sites were located in the Platte River; the other site was located in Clear Creek.

\section{5 $\quad K_{\mathrm{v}}$ profile for gaining streams}

In gaining streams, the $K_{\mathrm{v}}$ profiles show a decreasing trend with depth (Fig. 4). The cores were taken from the middle of the Platte River at the Clarks and Duncan sites in 2005 when this segment of the Platte River was nearly drying up (Chen et al., 2008). For the site west of North Bend, cores were taken from exposed streambed in 2008; at the site of Clear Creek, cores were taken from a very flat bank. Thus, the first cores at the two sites were not plotted into the $K_{\mathrm{V}}$ profiles for this trend analysis. In this analysis, only cores taken under the water table were used. When the sediments are above the water table, the hydrodynamics of the losing or gaining process no longer has an impact on the exposed sediments.

At the Clear Creek site, the six $K_{\mathrm{V}}$ values for the depth of $\sim 1.5-9 \mathrm{~m}$ show a decreasing trend. The $K_{\mathrm{v}}$ was $57.5 \mathrm{~m} \mathrm{~d}^{-1}$ for the $\sim 1.5-3 \mathrm{~m}$ depth; it decreased to $1.4 \mathrm{~m} \mathrm{~d}^{-1}$ at the depth of $9 \mathrm{~m}$. At the Clarks site on the Platte River, the eight $K_{\mathrm{v}}$ values decreased from $26.5 \mathrm{~m} \mathrm{~d}^{-1}$ from the $\sim 0-1.5 \mathrm{~m}$ depth to $0.01 \mathrm{~m} \mathrm{~d}^{-1}$ at the depth of $\sim 9-10.5 \mathrm{~m}$. At the Duncan site of the Platte River, the streambed sediment at $\sim 0$ $1.5 \mathrm{~m}$ depth had a high $K_{\mathrm{v}}$ value of $61.4 \mathrm{~m} \mathrm{~d}^{-1}$; the $K_{\mathrm{v}}$ value became $0.3 \mathrm{~m} \mathrm{~d}^{-1}$ at the 9 to $10.5 \mathrm{~m}$ depth. At the site of west of North Bend, the decreasing trend of $K_{\mathrm{v}}$ is also clear. The core for the $\sim 3-4.5 \mathrm{~m}$ depth was missing at this site, and its $K_{\mathrm{v}}$ value was not available. However, this did not affect the determination of the decreasing trend of $K_{\mathrm{v}}$. The six $K_{\mathrm{v}}$
Table 4. Maximum, minimum, and median values of $K_{\mathrm{V}}$ from the top five sediment cores at each test site.

\begin{tabular}{llll}
\hline \multirow{2}{*}{ Test } & \multicolumn{3}{c}{$K_{\mathrm{V}}$ values $\left(\mathrm{m} \mathrm{d}^{-1}\right)$} \\
\cline { 2 - 4 } site & Minimum & Maximum & Median \\
\hline Wood River & 0.001 & 1.3 & 0.34 \\
Platte River (P. R.) & 2.54 & 34.5 & 8.2 \\
north channel & & & \\
Lost Creek & 0.00008 & 1.3 & 0.009 \\
Spring Creek & 0.0008 & 10 & 0.01 \\
Clear Creek & 5.6 & 57.5 & 19.3 \\
P. R. North Bend & 0.72 & 16.9 & 1.9 \\
P. R. Clarks & 0.01 & 26.6 & 5.6 \\
P. R. Duncan & 0.83 & 61.4 & 13.9 \\
\hline
\end{tabular}

values decreased from $16.9 \mathrm{~m} \mathrm{~d}^{-1}$ in the top to $0.4 \mathrm{~m} \mathrm{~d}^{-1}$ in the bottom of the profile. The minimum, maximum, and median of $K_{\mathrm{V}}$ values for the top five cores are summarized in Table 4.

\section{Discussion}

As discussed in the introduction section, physical, chemical, and biological processes are typically involved in streambed clogging processes. This study was not aimed at separating the three major clogging processes at the four study sites under losing conditions. We will mainly interpret $K_{\mathrm{v}}$ spatial distribution patterns in losing streams and relate the patterns to filtration processes. The reduced $K_{\mathrm{V}}$ in these four losing study sites was probably the combined effects of the physical, chemical and biological processes.

\subsection{Hydrodynamic effects}

The motion of pore water provides the principal mechanisms for transport of sediment particles (Davis Jr., 1983) within the sediment matrix. So, the transport direction and deposition position of fine particles are controlled mainly by the hydrodynamic conditions in stream-aquifer systems. Under losing conditions, fine particles suspended in stream water can readily be carried into porous streambeds composed of sediments of sand size or larger, and then deposited due to a combination of gravitational settling and attachment to bed sediment surfaces (Packman et al., 2000a,b). Fine particles preferentially deposit at inflow regions on the streambed surface. Substantial accumulation of fine particles at these inflow locations can plug the uppermost layer of the streambed, affect the bulk porosity (Rehg et al., 2005), and thereby greatly decrease the vertical hydraulic conductivity in the streambed. Streambed particle filtration depends on overlying streamflow (Karwan and Saiers, 2012). The concentration of fine particles can be high in stream water during flooding, which provides the source of fine particulate matter 
for the clogging process. When the infiltrated water passes through the water-sediment interface and moves further into a depth, the concentration of suspended fine particles in the water reduces gradually. The degree of siltation due to the deposits of clay and colloids then decreases at a larger depth. This water infiltration process in losing segments produces streambeds that contain less fine materials at greater depth and causes less alteration of the original $K$ in the coarse sediments. Laboratory observation suggested that the fine particle penetration is in a limited thickness (for example, less than $50 \mathrm{~cm}$ ). Although our field investigation was not designed to detect the penetration depth of the clogging process, the $K_{\mathrm{v}}$ patterns from the study sites probably indirectly indicate that the streambed hydraulic conductivity can be affected to the depth greater than $5 \mathrm{~m}$. Lateral water filtration toward the stream banks can also clog the originally coarse sediments and form a low-permeability zone below the bank. The cores from the Spring Creek and Wood River sites were collected from the bank. The decreasing trend of $K_{\mathrm{V}}$ in the sediments below the river bank at these two sites was believed to be formed by lateral and downward infiltration processes under the losing conditions.

The magnitude of $K_{\mathrm{V}}$ values can reflect the clogging degree of the streambed and the penetration depth of the fine particles into the streambed. Among the four test sites under losing conditions, the smallest $K_{\mathrm{v}}$ value of $0.00008 \mathrm{~m} \mathrm{~d}^{-1}$ occurred in the top layer of the streambed in Lost Creek whereas the relatively high $K_{\mathrm{v}}$ value of $2.5 \mathrm{~m} \mathrm{~d}^{-1}$ occurred in the top layer of the Platte River north channel. According to the results of the in situ permeameter tests, we believe that the streambed at the Platte River north channel site and the Wood River site are under partially clogged conditions (or intermediate clogging), whereas the Lost Creek and Spring Creek sites are reaching the completely clogged stage and the channels at the two sites are covered by fine materials (silt and clay). In the intermediate stage, the streambed sediments are characterized by patchy distribution of silt/clay and fine-sand lenses and display a big spatial variation in streambed $K_{\mathrm{v}}$ values. For example, in the Platte River north channel, the greatest $K_{\mathrm{v}}$ value is about four orders of magnitude higher than the smallest $K_{\mathrm{V}}$ value in the upper layer of the streambed. Under the completely clogged condition, the streambed sediments are nearly fully covered by mostly low permeable sediments, e.g., $K_{\mathrm{v}}$ values in Lost Creek streambed were mostly (eight out of ten $K_{\mathrm{v}}$ values) less than $1 \mathrm{~m} \mathrm{~d}^{-1}$, ranging from 0.00008 to $2.4 \mathrm{~m} \mathrm{~d}^{-1}$.

Additionally, we can see from the $K_{\mathrm{v}}$ profiles in Fig. 4 that relatively larger $K_{\mathrm{v}}$ values (greater than $1 \mathrm{~m} \mathrm{~d}^{-1}$ ) mostly occur at $\sim 5-10 \mathrm{~m}$ depth in the losing streams. The $K_{\mathrm{v}}$ values for the alluvial aquifer in the study area (Chen et al., 2010) ranged commonly from 1 to $10 \mathrm{~m} \mathrm{~d}^{-1}$. Therefore, we speculate that the maximum depth of clogging processes into the streambeds may be $\sim 5-10 \mathrm{~m}$. This depth is in accordance with the modeling results of Chen (2007) that the infiltration depth of stream water in the streambed was about $8 \mathrm{~m}$.
In gaining streams, the opposite $K_{\mathrm{V}}$ distribution pattern can be attributed to the upward hydrodynamic condition: groundwater feeding the streambed by upward seepage. Under the upward flow conditions, fine particles that are strained between coarse particles, colloids, or algae become suspended, are lifted out of the streambed and then winnowed by the stream flow. With the disappearance of the fine particles, the sediments in the upper layer of streambeds become more unconsolidated and permeable than those in the lower layer. This furthermore results in greater $K_{\mathrm{v}}$ values in the upper layers (Fig. 4). Genereux et al. (2008) suggested that erosion and deposition are two processes that alter the hydraulic conductivity of streambeds and lead to temporal variations of streambed $K$ values. However, the effect of erosion and deposition processes is likely limited to the shallow part of streambeds, and it is not able to impact a large depth (for example, several meters) in small streams where stream flow rate is generally low.

\subsection{Chemical effects through the deposition of the colloidal particles}

The deposition of colloidal particles in a porous medium is relevant in siltation of streambeds (Packman et al., 2000a). Liu et al. (1995) reported that solution ionic strength influences the dynamics of colloidal deposition and transport in heterogeneous porous media. A rise in ionic strength will be beneficial for the deposition of colloidal particles. The ionic strength of a solution can be expressed as (Eby, 2004)

$$
I=\frac{1}{2} \sum m_{i} z_{i}^{2}
$$

where $m_{i}$ is the moles per liter of ion $i$ and $z_{i}$ is the charge of ion $i$. Ionic strength is approximately proportional to electrical conductivity.

According to the field measurements, the electrical conductivity of water in streambed sediments is smaller than those in stream water at each site (Table 1). In gaining streams, when stream water is fed by groundwater with a low EC value, the EC value in stream water decreases in upwelling zones. Thus, the ionic strength is reduced. This decrease can result in the increase of the mobility of colloidal particles and prevent them from deposition in the channel surface. This furthermore contributes to the greater $K_{\mathrm{v}}$ values in the upper layer of streambed sediments in the gaining streams. Conversely, in losing streams, when stream water with a higher EC value enters the subsurface, the total EC value in the subsurface environment can increase, resulting in the deposition of colloidal particles. This can contribute to the clogging process in the upper layer of streambed sediments in losing streams. 


\section{Conclusions}

We investigated streambed hydraulic conductivity in losing streams and in gaining streams. We first measured streambed $K_{\mathrm{V}}$ in the top layers of the channel sediments from eight study sites, four sites under losing conditions and the other four sites under gaining conditions; we then determined the $K_{\mathrm{V}}$ distribution of the streambed in a vertical profile at each test site.

We compared the hydraulic conductivity in the top layers of streambeds. In gaining streams, the streambeds consisted mainly of sand and gravel and were very permeable. The $K_{\mathrm{v}}$ values were generally greater than $1 \mathrm{~m} \mathrm{~d}^{-1}$, and in the range of 1 to $100 \mathrm{md}^{-1}$. The median $K_{\mathrm{v}}$ values from the Platte River with gaining conditions were greater than $33 \mathrm{~m} \mathrm{~d}^{-1}$. However, the median $K_{\mathrm{v}}$ value for the Platte River for the losing condition was only about $1.5 \mathrm{~m} \mathrm{~d}^{-1}$. In the losing streams, the streambed consisted mainly of fine sand, silt and clay if the channel was nearly fully silted, and consisted of poorly sorted sand and gravel which contained silt and clay lenses. The hydraulic conductivities were often smaller than $1 \mathrm{~m} \mathrm{~d}^{-1}$ and could be as small as $0.001 \mathrm{~m} \mathrm{~d}^{-1}$. Statistical analyses indicated that the $K_{\mathrm{v}}$ values from the four sites under losing stream conditions are significantly different from the $K_{\mathrm{v}}$ values from the four sites under gaining stream conditions. Among the four sites under losing stream conditions, the $K_{\mathrm{v}}$ values from the Lost Creek and Spring Creek sites are significantly different from the $K_{\mathrm{v}}$ values from the other two sites. This difference probably reflects that the clogging level in the former two sites differs from that in the latter two sites.

The vertical $K_{\mathrm{v}}$ profiles show two opposite vertical distribution patterns between the two types of streams. In the losing streams, $K_{\mathrm{v}}$ increased downward from the channel surface to depth of about 5 to $10 \mathrm{~m}$. This pattern resulted from physical, chemical and biological clogging mechanisms. Fine-grained material likely deposited in the pores in the top layers of the streambed. Less fine-grained material became available when the water migrated further downward. In the gaining streams, $K_{\mathrm{v}}$ values showed a decreasing trend. The upward flux suspended sediments, enhanced the pore spacing and elevated the $K_{\mathrm{v}}$ values in the top layers of the streambed. These mechanisms for elevating $K_{\mathrm{v}}$ became less effective at a larger depth.

Original depositional environments controlled largely the framework of sediment materials and thus affected the overall hydraulic conductivity of the sediments. However, postdepositional environments such as stream-groundwater exchange can relocate fine materials, induce chemical and biological processes, and eventually alter the original hydraulic conductivity. This post-depositional process has a very significant role in changing the magnitude of $K_{\mathrm{v}}$, and the alteration in $K_{\mathrm{v}}$ can reach several orders of magnitude.
Acknowledgements. The study was funded by the Central Platte, Tribasin, Upper Big Blue, and Lower Platte North Natural Resources Districts of Nebraska. The analysis was also partially supported by the National Natural Science Foundation of China (project no. 41072183). Matt Marxsen and Dan Sullivan operated the Geoprobe for EC logging and sediment coring of the streambeds.

Edited by: M. Gooseff

\section{References}

Banzhaf, S., Krein, A., and Scheytt, T.: Investigative approaches to determine exchange processes in the hyporheic zone of a low permeability riverbank, Hydrogeol. J., 19, 591-601, doi:10.1007/s10040-011-0707-4, 2011.

Bouwer, H.: Artificial recharge of groundwater: hydrogeology and engineering, Hydrogeol. J., 10, 121-142, 2002.

Chen, X. H.: Streambed hydraulic conductivity for rivers in southcentral Nebraska, J. Am. Water Resour. Assoc., 40, 561-574, 2004.

Chen, X. H.: Hydrologic connections of a stream-aquifer-vegetation zone in south-central Platte River valley, Nebraska, J. Hydrol., 333, 554-568, 2007.

Chen, X. H.: Depth-dependent hydraulic conductivity distribution patterns of a streambed, Hydrol. Process., 25, 278-287, doi:10.1002/hyp.7844, 2011.

Chen, X. and Chen, X. H.: Stream water infiltration, bank storage, and storage zone changes due to stream-stage fluctuations, J. Hydrol., 280, 246-264, doi:10.1016/S0022-1694(03)00232-4, 2003.

Chen, X. H., Burbach, M., and Cheng, C.: Electrical and hydraulic vertical variability in channel sediments and its effects on streamflow depletion due to groundwater extraction, J. Hydrol., 352, 250-266, 2008.

Chen, X. H., Song, J., and Wang, W.: Spatial variability of specific yield and vertical hydraulic conductivity in a highly permeable alluvial aquifer, J. Hydrol., 388, 379-388, doi:10.1016/j.jhydrol.2010.05.017, 2010.

Chen, X. and Ou, G.: Development of Groundwater Flow Model for the Lower Platte North Natural Resources District Area, Nebraska, University of Nebraska-Lincoln, Lincoln, NE, USA, Unpublished Report, p. 110, 2013.

Cui, Y. T., Wooster, J. K., Baker, P. F., Dusterhoff, S. R., Sklar, L. S., and Dietrich, W. E.: Theory of fine sediment infiltration into immobile gravel bed, J. Hydraul. Eng., 134, 1421-1429, 2008.

Davis Jr., R. A.: Depositional systems-A Genetic Approach to Sedimentary Geology, Prentice-Hall, INC., Englewood Cliffs, New Jersey, p. 669, 1983.

Dong, W. H., Chen, X. H., Wang, Z. W., Ou, G. X., and Liu, C.: Comparison of vertical hydraulic conductivity in a streambedsand bar system of a gaining stream, J. Hydrol., 450-451, 9-16, 2012.

Eby, G. N.: Principles of Environmental Geochemistry, Brooks/Cole - Thomson Learning, Pacific Grove, California, p. 514, 2004.

Elliott, A. H. and Brooks, N. H.: Transfer of nonsorbing solutes to a streambed with bed forms: Theory, Water Resour. Res., 33, 123136, 1997. 
Frostick, L. E., Lucas, P. M., and Reid, I.: The infiltration of fine matrices into coarse- grained alluvial sediments and its implications for stratigraphical interpretation, J. Geol. Soc., 141, 955965, 1984.

Genereux, D. P., Leahy, S., Mitasova, H., Kennedy, C. D., and Corbett, D. R.: Spatial and temporal variability of streambed hydraulic conductivity in West Bear Creek, North Carolina, USA, J. Hydrol., 358, 332-353, 2008.

Gerecht, K. E., Cardenas, M. B., Guswa, A. J., Sawyer, A. H., Nowinski, J. D., and Swanson, T. E.: Dynamics of hyporheic flow and heat transport across a bed-to-bank continuum in a large regulated river, Water Resour. Res., 47, W03524, doi:10.1029/2010WR009794, 2011.

Gooseff, M. N., Anderson, J. K., Wondzell, S. M., LaNier, J., and Haggerty, R.: A modelling study of hyporheic exchange pattern and the sequence, size, and spacing of stream bedforms in mountain stream networks, Oregon, USA, Hydrol. Process., 20, 24432457, 2006.

Gunkel, G. and Hoffmann, A.: Clogging processes in a bank filtration system in the littoral zone of Lake Tegel (Germany), in: the Proceedings of 5th International Symposium on Management of Aquifer Recharge, 10-16 June 2005, Berlin, Germany, 599-604, 2006.

Hancock, P. J.: Human impacts on the stream-groundwater exchange zone, Environ. Manage., 29, 763-781, 2002.

Hiscock, K. M. and Grischek, T.: Attenuation of groundwater pollution by bank filtration, J. Hydrol., 266, 139-144, 2002.

Karwan, D. L. and Saiers, J. E.: Hyporheic exchange and streambed filtration of suspended particles, Water Resour. Res., 48, W01519, doi:10.1029/2011WR011173, 2012.

Liu, D., Johnson, P. R., and Elimelech, M.: Colloid deposition dynamics in flow through porous media: role of electrolyte concentration, Environ. Sci. Technol., 29, 2963-2973, 1995.

Packman, A. I., Brooks, N. H., and Morgan, J. J.: Kaolinite exchange between a stream and streambed: Laboratory experiments and validation of a colloid transport model, Water Resour. Res., 36, 2363-2372, 2000a.
Packman, A. I., Brooks, N. H., and Morgan, J. J.: A physicochemical model for colloid exchange between a stream and a sand stream bed with bed forms, Water Resour. Res., 36, 2351-2361, 2000 b.

Rehg, K. J., Packman, A. I., and Ren, J.: Effects of suspended sediment characteristics and bed sediment transport on streambed clogging, Hydrol. Process., 19, 413-427, 2005.

Ren, J. and Packman, A. I.: Effects of background water composition on stream-subsurface exchange of submicron colloids, J. Environ. Eng., 128, 624-634, 2002.

Rosenberry, D. O. and Pitlick, J.: Effects of sediment transport and seepage direction on hydraulic properties at the sedimentwater interface of hyporheic settings, J. Hydrol., 373, 377-391, doi:10.1016/j.jhydrol.2009.04.030, 2009a.

Rosenberry, D. O. and Pitlick, J.: Local-scale variability of seepage and hydraulic conductivity in a shallow gravel-bed river, Hydrol. Process., 23, 3306-3318, 2009b.

Schubert, J.: Hydraulic aspects of riverbank filtration-field studies, J. Hydrol., 266, 145-161, 2002.

Song, J. X., Chen, X. H., Cheng, C., Summerside, S., and Wen, F. J.: Effects of hyporheic processes on streambed vertical hydraulic conductivity in three rivers of Nebraska, Geophys. Res. Lett., 34, L07409, doi:10.1029/2007GL029254, 2007.

Silliman, S. E., Ramirez, J., and McCabe, R. L.: Quantifying downflow through creek sediments using temperature time series: onedimensional solution incorporating measured surface temperature, J. Hydrol., 167, 99-119, 1995.

Stuyfzang, P. J., Juhasz-Holterman, M. H. A., and de Lange, W. J.: Riverbank filtration in the Netherlands: well fields, clogging and geochemical reactions, in: Riverbank Filtration Hydrology, Impacts on System Capacity and Water Quality, NATO Science Series IV, edited by: Hubbs, S. A., Springer, 119-153, 2006.

Wang, D.: Impacts of Water Pumping on Base Flow Trends in Selected Streams of Nebraska (Master's Thesis), University of Nebraska-Lincoln, Lincoln, NE, USA, p. 222, 2008.

Wett, B., Jarosch, H., and Ingerle, K.: Flood induced infiltration affecting a bank filtrate well at the River, J. Hydrol., 266, 222-234, 2002. 